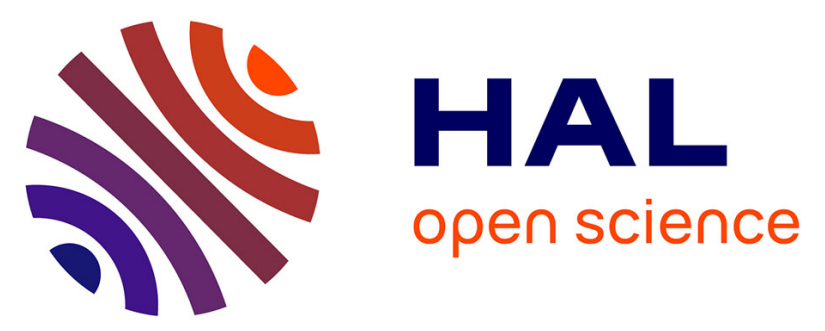

\title{
Modular organization and developmental activity of an Arabidopsis thaliana EF-1 alpha gene promoter
}

Catherine Curie, Michèle Axelos, Claude Bardet, Rossitza Atanassova, Nicole Chaubet, Bernard Lescure

\section{- To cite this version:}

Catherine Curie, Michèle Axelos, Claude Bardet, Rossitza Atanassova, Nicole Chaubet, et al.. Modular organization and developmental activity of an Arabidopsis thaliana EF-1 alpha gene promoter. Molecular Genetics and Genomics, 1993, 238, pp.428-436. 10.1007/BF00292002 . hal-03084189

\section{HAL Id: hal-03084189 \\ https://hal.science/hal-03084189}

Submitted on 20 Dec 2020

HAL is a multi-disciplinary open access archive for the deposit and dissemination of scientific research documents, whether they are published or not. The documents may come from teaching and research institutions in France or abroad, or from public or private research centers.
L'archive ouverte pluridisciplinaire HAL, est destinée au dépôt et à la diffusion de documents scientifiques de niveau recherche, publiés ou non, émanant des établissements d'enseignement et de recherche français ou étrangers, des laboratoires publics ou privés.

\section{(ㅇ)(1) $\$$}

Distributed under a Creative Commons Attribution - NonCommercial - NoDerivatives| 4.0 


\title{
Modular organization and developmental activity of an Arabidopsis thaliana EF-1 $\alpha$ gene promoter
}

\author{
Catherine Curie $^{1}$, Michèle Axelos ${ }^{1}$, Claude Bardet ${ }^{1}$, Rossitza Atanassova ${ }^{2}$, Nicole Chaubet ${ }^{2}$, Bernard Lescure ${ }^{1}$ \\ ${ }^{1}$ Laboratoire de Biologie Moléculaire des Relations Plantes-Microorganismes, CNRS-INRA, BP 27, F-31326 Castanet-Tolosan, France \\ ${ }^{2}$ Institut de Biologie Moléculaire des Plantes, CNRS, 12 rue du Général Zimmer, F-67000 Strasbourg, France
}

Received: 19 September 1992/Accepted: 9 November 1992

\begin{abstract}
The activity of the Arabidopsis thalana A1 EF$1 \alpha$ gene promoter was analyzed in transgenic Arabidopsis plants. The $5^{\prime}$ upstream sequence of the A1 gene and several promoter deletions were fused to the $\beta$-glucuronidase (GUS) coding region. Promoter activity was monitored by quantitative and histochemical assays of GUS activity. The results show that the A1 promoter exhibits a modular organization. Sequences both upstream and downstream relative to the transcription initiation site are involved in quantitative and tissue-specific expression during vegetative growth. One upstream element may be involved in the activation of expression in meristematic tissues; the downstream region, corresponding to an intron within the $5^{\prime}$ non-coding region (5'TVS), is important for expression in roots; both upstream and downstream sequences are required for expression in leaves, suggesting combinatorial properties of EF-1 $\alpha$ cis-regulatory elements. This notion of specific combinatorial regulation is reinforced by the results of transient expression experiments in transfected Arabidopsis protoplasts. The deletion of the 5'IVS has much more effect on expression when the promoter activity is under the control of A1 EF- $1 \alpha$ upstream sequences than when these upstream sequences were replaced by the $35 \mathrm{~S}$ enhancer. Similarly, a synthetic oligonucleotide corresponding to an $\mathrm{A} 1 \mathrm{EF}-1 \alpha$ upstream cis-acting element (the TEF1 box), is able to restore partially the original activity when fused to a TEF1-less EF1- $\alpha$ promoter but has no significant effect when fused to an enhancer-less $35 \mathrm{~S}$ promoter.
\end{abstract}

Key words: Arabidopsis thaliana - Development - Meristems - Plant promoter

\section{Introduction}

The eukaryotic elongation factor, $\mathrm{EF}-1 \alpha$, plays a central role in the translational process by promoting the bind-

Communicated by C.A.J.J. van den Houndel

Correspondence to: $\mathrm{B}$. Lescure ing of aminoacyl-tRNA to $80 \mathrm{~S}$ ribosomes. It has been suggested that this factor might be involved in other aspects of cellular regulation by interacting with the cytoskeleton and the mitotic apparatus and that it is probably responsible for the accumulation of aminoacyltRNA present in high levels during early oocyte development in Xenopus laevis (Riis et al. 1990 and references therein). The expression level of EF- $1 \alpha$ is a major limiting step for protein synthesis and is correlated with cellular growth state and the ageing process (Riis et al. 1990). In plants, recent studies have shown that, during development. EF- $1 \alpha$ is constitutively expressed, with increased expression corresponding to regions of high protein synthesis, including meristems, rapidly growing tissues and developing gametophytes (Ursin et al. 1991). These data indicate that the analysis of promoter elements involved in the activation of EF- $1 \alpha$ expression is of value for studying interrelationships between protein synthesis and developmental control. In addition, since the formation of new organs throughout plant life results from cell divisions which are confined to specialized regions, the meristems, the characterization and study of EF- $1 \alpha$ promoter cis-acting elements which could specifically control gene expression in meristematic tissues is of particular interest.

In Arabidopsis thaliana, EF- $1 \alpha$ is encoded by a small multigene family of four members (A1-A4; Axelos et al. 1989) which are all actively transcribed (Liboz et al. 1990). The analysis of the A1 gene promoter by transient expression experiments has shown that activation of expression in Arabidopsis protoplasts depends on several distinct elements located both upstream and downstream of the transcription initiation site (Curie et al. 1991). Firstly, sequences located between -1620 and -289 relative to the transcription initiation site ( $\mathrm{X}$ in Fig. 1) are required for maximum activity. Secondly, a cis-acting element, the TEF1 box, has been accurately localized between positions -106 and -82 . Thirdly, DNA sequences in an intron located within the $5^{\prime}$ noncoding region of the A1 gene (5'IVS in Fig. 1) are essential for expression in protoplasts. 
In this paper, we present results of studies of the role of these promoter elements in gene expression in transgenic Arabidopsis plants. We also report data suggesting a functional interaction between cis-elements located upstream and downstream of the transcription initiation site.

\section{Materials and methods}

Construction of expression vectors. The basis of all constructions used to transform Arabidopsis was the plant transformation vector pBI101 (Jefferson et al. 1987). Mutations of the A1 promoter fused to the GUS reporter gene, previously described by Curie et al. (1991) were introduced into the binary vector $\mathrm{pBI} 101$, replacing of the original vector sequences located between the EcoRI and the HindIII sites. The plasmids p35S, p-289, p-70 and p-2894IVS, used for transient assays, have been already described (Axelos et al. 1989; Curie et al. 1991). The plasmid p35S-90 was constructed by removing CaMV 35S promoter sequences upstream of the EcoRV site at position -90 relative to the transcription initiation site. For the plasmids p-70.TEF, p-70.FET, p35S90.TEF and p35S-90.FET, a double-stranded synthetic oligonucleotide, corresponding to the sequence overlapping the TEF1 element of the A1 gene (5'ATTCACGGCTAAACAGGGGATAATGGTAATTTAAAGAAT $3^{\prime}$ ), was fused in both orientations (designated TEF for direct or FET for inverted orientation) upstream of positions -70 and -90 in the plasmids $p-70$ and p35S-90, respectively. The chimeric p35S-A1 and p35S-A1 1 IVS plasmids were obtained by ligation of PCR amplification products corresponding to sequences of the 35S promoter located upstream of position -17 , to PCR fragments corresponding to sequences of $\mathrm{p}-289$ or $\mathrm{p}-2894 \mathrm{IVS}$ located downstream of position -17 relative to the transcription initiation site. In all cases, the chimeric constructs were verified by sequencing.

Transient gene expression assays. Transfection experiments were carried out using Arabidopsis thaliana protoplasts isolated from cell suspension cultures (T87 cell line), as previously described (Axelos et al. 1992).

Transformation and analysis of transgenic plants. Arabidopsis thaliana, ecotype $\mathrm{C} 24$, was transformed with Agrobacterium tumefaciens according to the root explant method described by Valvekens et al. (1988). Seeds obtained from self-fertilized primary transformants (T1) were germinated on GM medium supplemented with 50 $\mu \mathrm{g} / \mathrm{ml}$ kanamycin (Valvekens et al. 1988). After two weeks, the kanamycin-resistant plants (T2) were transferred to kanamycin-free medium. For quantitative determinations of GUS activity, organs were harvested from 4 to 6-week-old plants. Leaves (6th leaf of the basl rosette) were harvested at the 10 to 12-leaf stage and roots were harvested after bolting of the floral stem. Samples were frozen in liquid $\mathrm{N}_{2}$ and kept at $-70^{\circ} \mathrm{C}$ until assay. The histochemical analysis of GUS activity was performed either in organs harvested from $\mathrm{T} 2$ adult plants or in young seedlings of the T3 progeny grown on kanamycin-free medium.

Fluorometric and histochemical analysis of GUS activity. GUS assays and histochemical staining were performed essentially according to Jefferson (1987). For GUS activity measurements in transgenic plants, extracts were prepared by grinding the tissues with sand in lysis buffer, in the presence of Polyclar AT. The extracts were cleared by centrifugation and filtration through glass wool. GUS activity of plant extracts or protoplasts samples was measured by fluorometry. Enzymatic activity was expressed as nanomol 4-methylumbelliferone (MU) produced per minute per milligram of protein, at $37^{\circ} \mathrm{C}$, using 4-methylumbelliferyl- $\beta$-D-glucuronide as substrate. Protein concentration in the cellular extracts was determined by the method of Bradford (1976) with BSA as a standard. For GUS staining, plant organs or whole young seedlings were immersed in $0.5 \mathrm{mg} / \mathrm{ml} 5$-bromo-4chloro-3-indolyl- $\beta$-D-glucuronic acid solution and infiltrated under vacuum during $15 \mathrm{~min}$. After a $16 \mathrm{~h}$ incubation period at $37^{\circ} \mathrm{C}$, the plant material was cleared in hot $70 \%(\mathrm{v} / \mathrm{v})$ ethanol or in $6 \%$ sodium hypochlorite, then stored in $70 \%$ ethanol.

\section{Results}

Expression of EF-1 $\alpha$ promoter-GUS gene fusions in transgenic Arabidopsis

Mutations of the A1 promoter involving elements identified in transient assays (Curie et al. 1991) were fused to the GUS reporter gene and introduced into a binary vector derived from the plasmid pBI101 (Jefferson et al. 1987). A schematic representation of these constructs is shown in Fig. 1. The -1620 construct corresponds

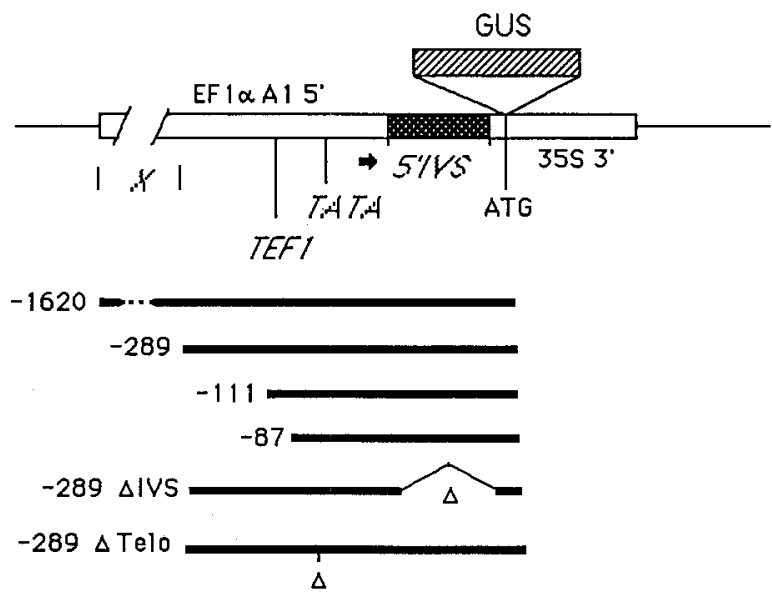

Fig. 1. Constructs used for Arabidopsis transformation. In the upper part of the figure the characteristic elements of the A1 gene promoter are indicated (see text for details). Deletions of the A1 promoter, illustrated in the lower part of the figure, were fused to the GUS reporter gene and introduced into a binary vector derived from the plasmid pBI101 (Jefferson et al. 1987). The $5^{\prime}$ end point of each construct is given relative to the transcription start site of the A1 gene 
to the full-length promoter. In the -289 and the -111 constructs, the $\mathrm{X}$ element has been deleted. The -87 construct, in which the $\mathrm{X}$ element and the TEF1 box have been deleted, only retains the functional element(s) located within the $5^{\prime}$ intron. In the -289 AIVS construct, the TEF1 box is conserved, but the $\mathrm{X}$ and the $5^{\prime}$ IVS elements have been deleted. In the $-289 \Delta$ Telo construct, we have removed a sequence corresponding to the Telo box (Axelos et al. 1989), a conserved motif homologous to the repeats of Arabidopsis telomeres (Richards and Ausubel 1988). This motif is observed at the same location within all the plant EF-1 $\alpha$ promoters characterized up to now: the four Arabidopsis promoters (Axelos et al. 1989; Liboz et al. 1990) and a tomato promoter (Shewmaker et al. 1990).

Transgenic Arabidopsis plants were generated by using an Agrobacterium-mediated transformation system (Valvekens et al. 1988). For each construct, 7 to 9 independent T2 transgenic plants were analysed for GUS activity. The quantitative data obtained in roots, or in leaves harvested from adult plants are reported in Fig. 2. Depending on the construct, a 5 to 50 -fold range in GUS specific activity was observed. For the full-length promoter (construct -1620), the GUS activities obtained in roots varied from approximately $450 \mathrm{nmol}$ to $3000 \mathrm{nmol}$ of 4-methylumbelliferone $/ \mathrm{min} / \mathrm{mg}$ protein. In

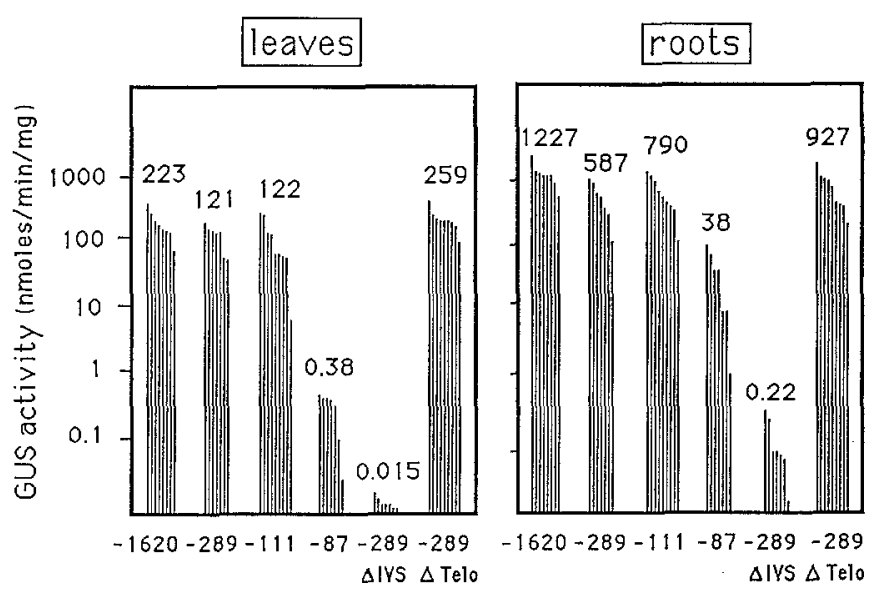

\begin{tabular}{|l|c|c|c|}
\hline \multicolumn{1}{|c|}{ ratio } & leaves & roots & $\begin{array}{c}\text { transient } \\
\text { expression }\end{array}$ \\
\hline$-1620 /-289$ & 1.8 & 2.1 & 2 \\
$-111 /-87$ & 320 & 21 & 10 \\
$-289 /-289 \Delta$ IVS & 8000 & 2700 & $15-20$ \\
$-289 /-289 \Delta$ Telo & 0.5 & 0.6 & 2 \\
\hline
\end{tabular}

Fig. 2. Effect of A1 promoter deletion on GUS expression levels in leaves and roots of transgenic Arabidopsis plants. Upper panels. GUS activity (plotted on a $\log$ scale, in $\mathrm{nmol} \mathrm{MU} / \mathrm{min} / \mathrm{mg}$ protein) measured in rosette leaves and roots from $\mathrm{T} 2$ adult plants containing the full-length promoter construct $(-1620)$ or the promoter deletion constructs illustrated in Fig. 1. Each bar corresponds to the mean value obtained from two independent plants of the same transformant. The average GUS activity from plants containing the same construct is indicated in the panels. Lower panel. GUS activity ratios obtained with the various constructs, calculated for leaves and roots of transgenic plants and for transient expression experiments. leaves the specific activities observed were from 65 to $480 \mathrm{nmol} / \mathrm{min} / \mathrm{mg}$ protein.

When the $X$ element was deleted $(-289$ and -111 constructs), on average a two-fold decrease in GUS activity was obtained in roots and leaves. As observed for transient assays (Curie et al. 1991), no variation in GUS was observed between the -289 and -111 constructs. Taking into account the variation in GUS activity for a given construct between independent transformed plants, the significance of the decrease of activity between the full-length promoter and the -289 or -111 constructs remains uncertain.

The deletion of both X element and TEF 1 box (construct -87 ) had a more marked effect causing a 20 and 300 -fold decrease of the GUS activity relative to the -111 construct, in roots and leaves, respectively. However, these activities remained much higher than the background observed in untransformed tissue, suggesting that one or several cis-acting elements may be located downstream of the TEF1 box, which are sufficient by themselves to promote this level of activity. Moreover, the role of this(these) putative downstream element(s) seems to be more important in roots than in leaves, since the effect of the deletion of the TEF 1 box appeared to be approximately fifteen-fold less in roots than in leaves.

The deletion of the $5^{\prime}$ intron ( $-289 \Delta$ IVS construct) had a dramatic effect on the expression both in roots and leaves: a 2500- and 8500-fold decrease in the activity, respectively, was observed relative to the -289 construct. The residual activity of the deleted promoter was only slightly higher than the experimental background level.

In the construct $-289 \Delta$ Telo, the Telo box AAACCCTAA (Axelos et al. 1989), located at positions $-62 /-53$ bp relative to the transcription start, was deleted. This deletion led to a two-fold increase in the GUS activity relative to the -289 construct. These results suggest that this conserved structural element is not essential for expression, at least under the experimental conditions used to examine its putative functions.

Figure 3 shows the histochemical GUS activity in representative plants transformed using the constructs reported in Fig. 1. Young seedlings containing the fulllength promoter ( -1620 construct) appeared to have constitutive GUS activity (Fig. 3A). Close inspection of several independent transgenic plants revealed a less intense GUS staining in the region of the hypocotyl. In older plants, constitutive expression was observed using the $-1620,-289$ and -111 constructs (data not shown and Figs. 3 B-3D). In all cases, the staining was more pronounced in the root meristematic region and in the vascular tissues.

In adult plants, the deletion of both the $\mathrm{X}$ element and the TEF1 box in the -87 construct led to a strong decrease of GUS staining in leaves (Figs. 3E, F). However, in rosette leaves, GUS activity was detected within the vascular tissues and in the hydathodes at the ends of veins along the leaf margins (Fig. $3 \mathrm{~F}$ ). In agreement with the quantitative data reported in Fig. 2, transgenic plants containing the -87 construct had strongly stain- 

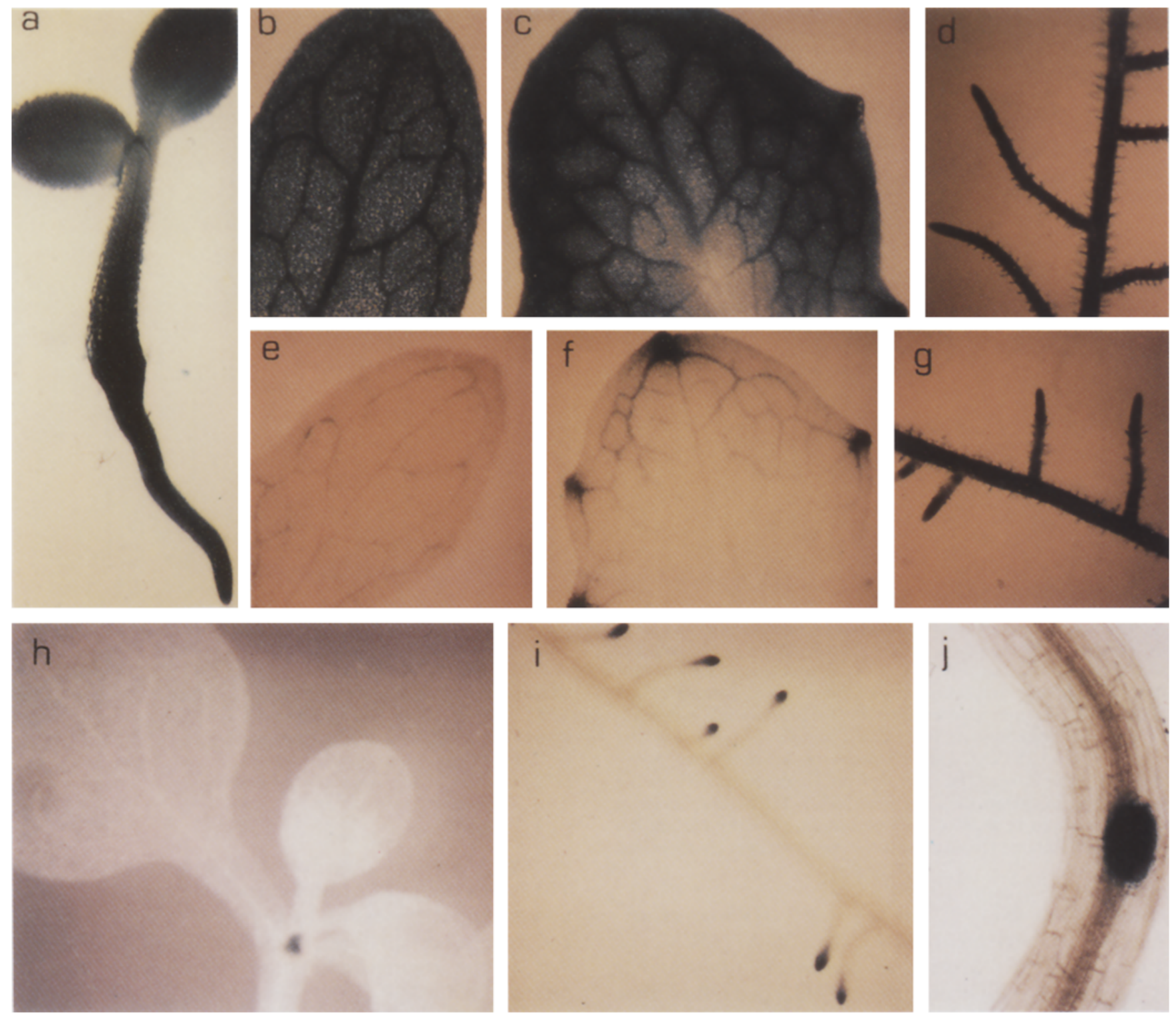

Fig. 3a-j. Histochemical localization of GUS activity in transgenic Arabidopsis plants. a Four-day-old seedling containing the -1620 construct; b cauline leaf, c rosette leaf and d roots from adult plants containing the -111 construct; e cauline leaf, f rosette leaf

ing roots (Fig. $3 \mathrm{G}$ ). Like the constructs containing the upstream domains, this staining appeared to be more pronounced in the root meristematic regions (Fig. $3 \mathrm{G}$ ). In young seedlings, GUS activity was also observed in cotyledons and hypocotyls but not in young leaves and shoot meristems (data not shown).

The deletion of the X element and 5'IVS in the -289 $\triangle I V S$ construct had a dramatic effect on GUS expression. Interestingly, in young seedlings and in older plants, the location of the staining was restricted to the apical and the lateral root meristems (Figs. $3 \mathrm{H}, \mathrm{I}$ and data not shown). Figure $3 \mathrm{~J}$ shows that this activity is induced early during the formation of a lateral root meristem. These data show that TEF1 box and 5'IVS sequences are both required for maximal activity, especially in leaves. and $\mathbf{g}$ roots from adult plants containing the -87 construct; h young seedling at the two-leaf stage, $\mathbf{i}$ roots from adult plant and $\mathbf{j}$ root from young seedling showing a lateral root primordia, all containing the -2894 IVS construct

\section{Transient assays indicate functional interaction between} the promoter elements

We have analyzed the effect of the 5'IVS deletion on expression in protoplasts, when the TEF1 box is replaced by the CaMV 35S enhancer. The results obtained are shown in Fig. 4. A $5^{\prime}$ deletion of the A1 promoter up to the position -289 ( -289 construct), mediated a GUS activity of the same magnitude as that obtained using the $35 \mathrm{~S}$ promoter ( $35 \mathrm{~S}$ construct). As already reported (Curie et al. 1991), using the -289 construct lacking the 5'IVS ( $-289 \Delta$ IVS construct), the GUS activity was 15 to 20 -fold lower than that obtained with the -289 construct. In the plasmids $35 \mathrm{~S}-\mathrm{A} 1$ and $35 \mathrm{~S}-\mathrm{A} 1$ $\triangle \mathrm{IVS}$, the intron plus and -minus constructs were made such that each mRNA produced was identical to that 

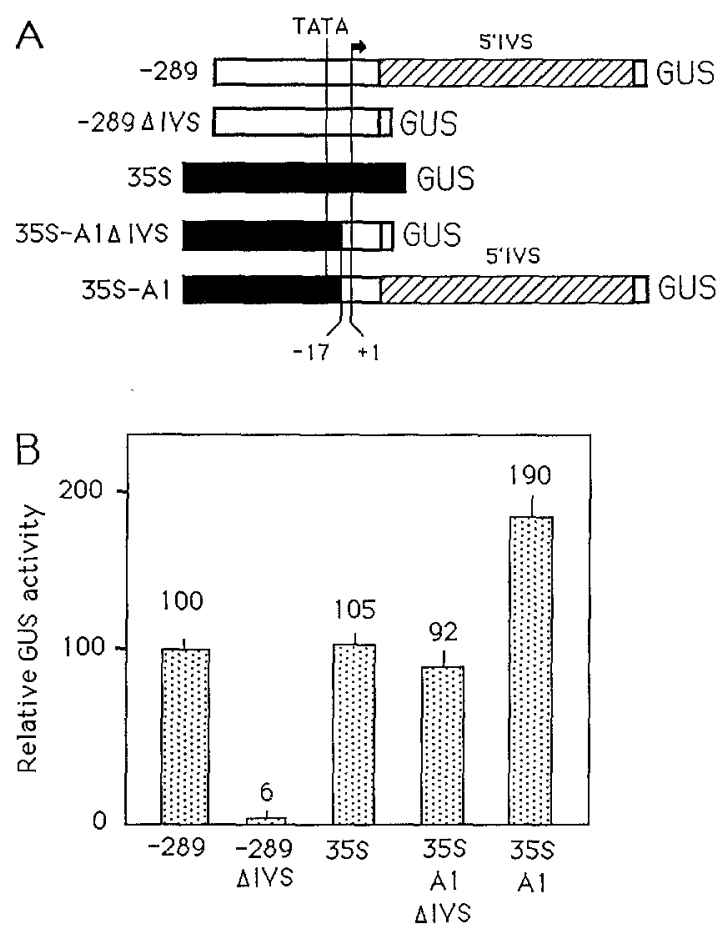

Fig. 4A, B. Influence of upstream cis-acting elements on the activation of the expression mediated by the $5^{\prime}$ intron of $\mathrm{A} 1$ gene in transfected Arabidopsis protoplasts. A schematic representation of plasmids used in transient assays is shown in A. Details of the construction of chimeric genes are indicated in Materials and methods. The A1 sequences are represented by open boxes (promoter) or striped boxes ( 5 IVS). The $35 \mathrm{~S}$ promoter sequences are represented by filled boxes. The indicated positions are relative to the transcription initiation site. The relative GUS activities shown in B are normalized to $\mathrm{p}-289(72 \mathrm{nmol} / \mathrm{min} / \mathrm{mg}$ protein $)$ and are the mean of data obtained from at least three independent transfections

expected from the -289 or the $-289 \Delta$ IVS construct. The GUS activity mediated by the $35 \mathrm{~S}-\mathrm{A} 1 \mathrm{AIVS}$ construct was slightly lower than those driven by the $35 \mathrm{~S}$ or the -289 promoter and eleven-fold higher than that obtained using -289 AIVS construct. This clearly demonstrates that the effect of the 5'IVS cannot be explained by an increase of the pre-mRNA stability alone or by more efficient export of RNA to cytoplasm. The addition of the A1 5'IVS in the chimaeric construct 35S-A1 led to a two-fold increase in the GUS activity relative to $35 \mathrm{~S}-\mathrm{A} 1$, in contrast to the 15 to 20 -fold increase seen when expression was under the control of the upstream A1 promoter sequences. This moderate activation was also observed when the 5'IVS was replaced by the intron which interrupts the coding region of the A1 gene (C. Curie, unpublished observation).

In a second series of experiments, we analyzed whether the activation of expression due to the upstream TEF1 element, located between positions -106 and -82 (Curie et al. 1991), depended on downstream sequences of the A1 promoter. A 40 bp synthetic double-stranded oligonucleotide, overlapping the TEF1 box, was fused in both orientations to an A1 deleted for the TEF1 box, or to a $35 \mathrm{~S}$ promoter deleted for the $35 \mathrm{~S}$ enhancer (Fig. 5). These constructs were tested for the ability of the TEF1 box to restore the promoter activity. Both
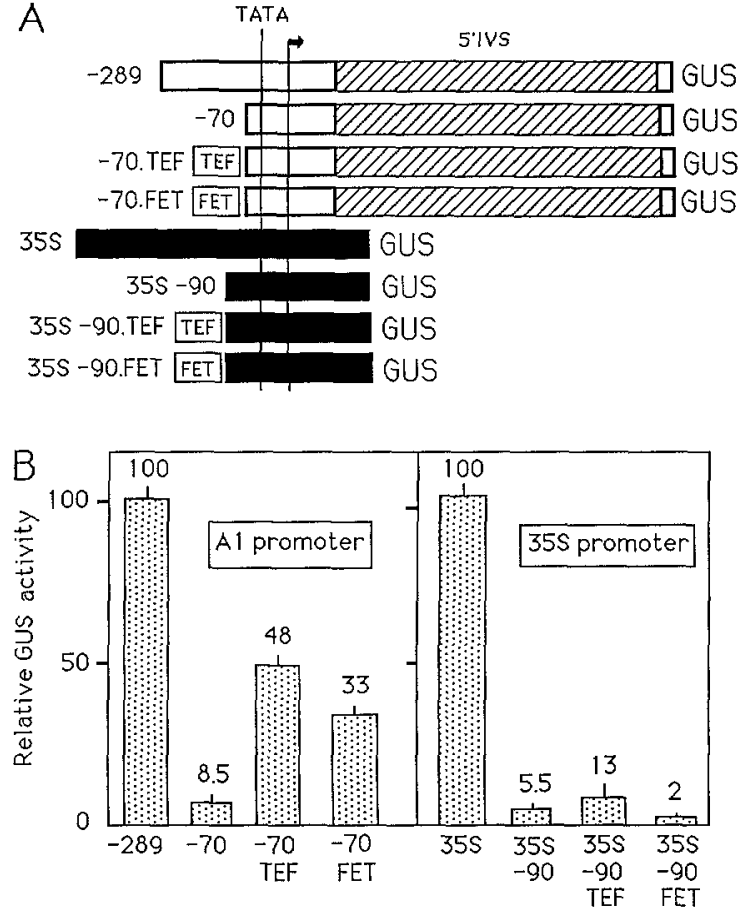

Fig. 5A, B. Transient assays of the activation of deleted A1 and $35 \mathrm{~S}$ promoters by a synthetic $T E F 1$ box. A Schematic representation of plasmids used for transient assays. TEF represents a synthetic oligonucleotide corresponding to a sequence overlapping the TEF1 box (see Materials and methods). FET is the same oligonucleotide in the opposite orientation. B GUS activities. The relative GUS activities are normalized to $\mathrm{p}-289$ (A1 promoter) or to $\mathrm{p} 35 \mathrm{~S}$ (35S promoter). Other abbrevations and details are as in Fig. 4

deleted promoters gave very low levels of expression. The fusion of the TEF 1 oligonucleotide to the -70 deletion increased expression by 6 - and 4 -fold in the correct and inverse orientations respectively. This represents half (in the original orientation) and one-third (in the reverse orientation) of the activity of the -289 or -111 constructs. In contrast, the fusion of the TEF1 oligonucleotide to the enhancer-less $35 \mathrm{~S}$ had a negligable effect. A slight increase in GUS activity was observed in one orientation and a decrease in the opposite one.

\section{Discussion}

The overall strength of a given promoter, as well as its particular developmental and tissue-specific regulatory program, is determined by the combination and spatial orientation of cis-acting elements, and by the presence and regulatory state of the nuclear factors that interact with them (reviewed by Dynan 1989). In plants, the viral CaMV 35S promoter offers a good example of such a modular organization (Benfey and Chua 1990). The data reported in this work show that the promoter of the constitutive plant gene $\mathrm{A} 1 \mathrm{EF}-1 \alpha$ is similarly organized. The activation of the A1 EF- $1 \alpha$ gene expression depends on several cis-acting domains which can individual confer distinct patterns of expression during development. In addition, we have shown that these domains 
can combine their effects in a specific, cooperative manner.

The TEF1 element. In higher plants, new organs arise from the activity of meristems throughout the life cycle. Therefore, understanding the mechanisms regulating meristem activity is one of the prerequisites for the understanding of plant development (Sussex 1989). Surprisingly, little is known about the control of gene expression in these specialized regions. Few plant genes have been characterized whose expression is associated with meristems or rapidly growing tissues (Dobres and Thompson 1989; Koning et al. 1991; Medford et al. 1991; Ursin et al. 1991; Atanassova et al. 1992; Hemerly et al. 1992; Pri-Hadash et al. 1992). For histone genes, the restricted expression in meristems is consistent with that expected for cycling cells (Koning et al. 1991, Atanassova et al. 1992, Lepetit et al. 1992). The more complex pattern of expression observed for the tomato dUTPase (Pri-Hadash et al. 1992) or EF-1 $\alpha$ genes (Ursin et al. 1991) is probably due to developmental programs superimposed on an activation process associated with cell multiplication. In this work, we have shown that a DNA domain of the A1 EF-1 $\alpha$ gene promoter, located between positions -289 and +55 relative to the transcription initiation site is involved in the activation of expression in meristematic tissues (Fig. 3). Several lines of evidence suggest that the TEF1 box (located between positions -106 and -82 ) is involved in this meristematic expression. Firstly, deletion of sequences located upstream of the TEF1 box, from position -289 down to -111 , does not significantly affect the level of expression in either transient assays (Curie et al. 1991) or in transgenic plants (Fig. 2) and has no effect on the distribution of GUS staining during vegetative growth (Fig. 3 and data not shown). Second, by gel retardation experiments, we have previously shown (Curie et al. 1991) that between positions -289 and +46 , the TEF1 box is the only sequence able to specifically interact in vitro with nuclear proteins. Third, sequence homologies found between the four $A$. thaliana and a single Lycopersion esculentum $\mathrm{EF}-1 \alpha$ promoters, together with functional data, suggest that the sequence AGGGGCANNNNNGTAANT is a basic motif required for the function of the TEF1 box (Curie et al. 1992); this motif is also found at the same location within a tobacco thio 2 gene promoter (Fig. 6), a gene which is specifically expressed in rapidly growing plant tissues (Brujidou et al. 1993). As discussed below, we cannot exclude the possibility that downstream elements, being between positions -82 and +55 , may also participate independently or cooperatively in the activation in meristematic tissues. Nevertheless, it will be interesting to characterize the genes encoding transcriptional factors interacting with the TEF1 box and to study their roles in controlling gene expression during the plant cell cycle.

The $5^{\prime}$ intron activation. In most functional studies of promoter activity, major attention has been focused on elements located upstream of the transcriptional start site. However, it has become evident that a large number of genes utilize elements that are located downstream of the start site. In many cases, regulatory sequences have been found within intervening sequences that interrupt $5^{\prime}$ untranslated regions (for examples, see Evans and Scrapulla 1988; Chung and Perry 1989; Ripe et al. 1989; Bruhat et al. 1990). It is noteworthy that $5^{\prime}$ introns are observed in all the higher eukaryotic EF- $1 \alpha$ genes characterized up to now (Lendstra et al. 1986; Hovemann et al. 1988; Uetsuki et al. 1989; Axelos et al. 1989; Liboz et al. 1990; Shewmaker et al. 1990). The conservation of this structural organization during the evolution potentially reflects an important role played by these 5'IVS in the control of expression of these genes. However, functional studies on the role of these EF-1 $\alpha$ 5'IVS in controlling expression have been conducted only in Arabidopsis. The results reported in Figs. 2 and 3 clearly indicate that this element is essential for the high level of activity of the A1 gene and strongly suggest that the effect of the 5'IVS deletion is mainly due to the loss of one or several internal cis-acting elements rather than a post-transcriptional effect as suggested for the intron 1 of Zea mays Adh1 or Shrunken1 genes (Luehrson and Walbot 1991; Maas et al. 1991). This assumption is reinforced by the observation that, in transient expression experiments, the $5^{\prime}$ IVS deletion has only a moderate effect on the GUS activity directed by the CaMV $35 \mathrm{~S}$ enhancer (Fig. 4), presumably because the downstream elements interact specifically with upstream elements in the A1 promoter. The analysis of DNA sequences corresponding to the A1 $5^{\prime}$ IVS reveals two motifs (Fig. 7), which are absent from the otherwise conserved $5^{\prime}$ noncoding sequences of the genes A2, A3 and A4 (Axelos et al. 1989). The first one, located at the position +40

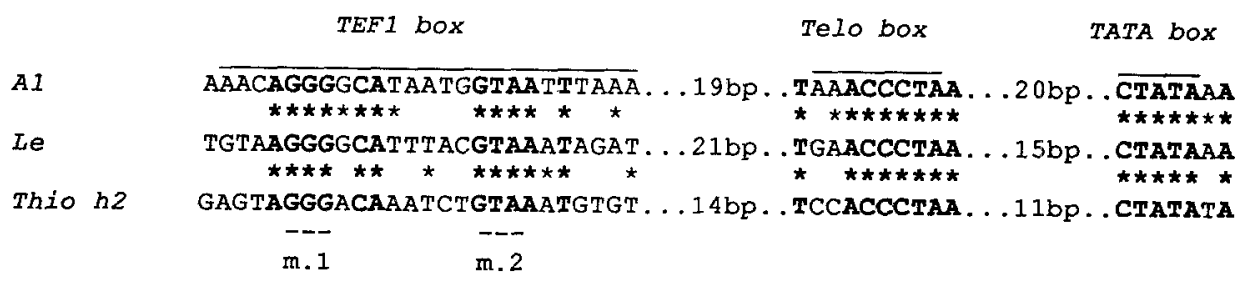

Fig. 6. Conservation of the relative organization of TEF1, Telo and TATA boxes between the Arabidopsis and tomato EF-1 $\alpha$ gene promoters (Axelos et al. 1989; Shewmaker et al. 1990) and the tobacco thio 2 gene promoter (Marty 1992). Identical bases are indicated by asterisks between the sequences. The overlined A1 TEF1

sequence represents the region protected against $\mathrm{OP}-\mathrm{Cu}$ cleavage by nuclear factors (Curie et al. 1991). $\mathrm{m} .1$ and $\mathrm{m} .2$ indicate the locations of mutations that affect the interaction of the TEF1 box with the corresponding transcriptional factors (Curie et al. 1992); m.1, AAA instead of GGG; m.2, AGC instead of GTA 
A

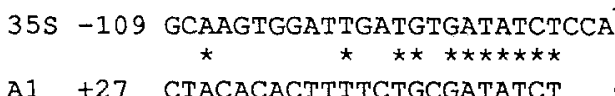

A1. +27 CTACACACTTTTCTGCGATATCT as 1

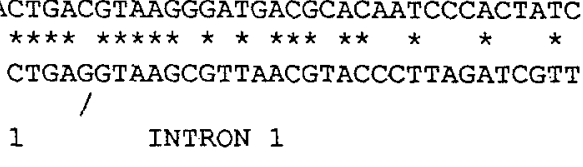

GGTAAGCGTTAACGTACCCTTAGATCGTT

INTRON 1

\section{B}

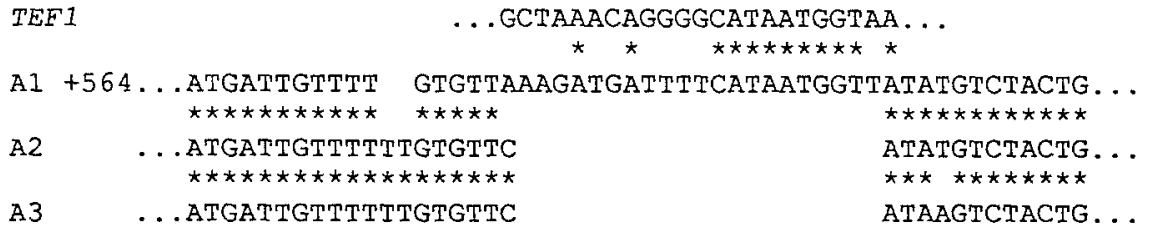

Fig. 7A, B. Putative downstream cisacting elements within the $5^{\prime}$ intron of the A1 gene. A Sequence similarities between the CaMV 35S promoter and the exon1/intron1 A1 gene sequences. The location in the $35 \mathrm{~S}$ promoter of the as1 (or OCS) element (Bouchez et al. 1989; Benfey et al. 1989) is indicated. The indicated positions are relative to the transcription initiation site. B Sequence similarities between the 5'TVS sequences of the $\mathrm{A} 1, \mathrm{~A} 2$ and $\mathrm{A} 3$ genes and between the TEF1 sequence and the 5 IVS of the A1 gene. The position indicated for the A1 sequence is relative to the transcription initiation site relative to the transcription initiation site and overlapping the junction between the exon1 and the intron1 (Fig. 7A), is highly homologous to a region of CaMV $35 \mathrm{~S}$ enhancer containing the ocs (or ast) element (Ellis et al. 1987). The ocs or as 1 elements are promoter components of several TDNA and plant viral genes (Bouchez et al. 1989). This element directs tissue-specific expression patterns with higher activities in roots, principally in the root meristematic region (Benfey et al. 1989) and interacts with transcription factors (OCSTF, ASF-1 and HBP-1a) that have been characterized from both dicots and monocots (Lam et al. 1989; Fromm et al. 1989; Tokuhisa et al. 1990). The putative ocs sequence found at the junction between exon1 and intron1 could be the downstream element responsible for the GUS activity observed in roots when the $\mathrm{X}$ and the TEF1 upstream elements were deleted (construct -87 in Figs. 2 and 3). Studies are in progress to test this hypothesis. Within the 5'IVS, a second DNA sequence (Fig. 7B) located $592 \mathrm{bp}$ downstream the transcription initiation site, is homologous for 9 consecutive bp to the TEF1 core motif. Curiously, this sequence corresponds to an insert which disrupts the strong conservation observed within the 5'IVS between the genes A1, A2 and A3 (Fig. 7B and Axelos et al. 1989). However, it is unlikely that this sequence is a $T E F 1$ box, since we have recently shown that the block of $\mathrm{G}$ residues in the TEF1 box, found just upstream of the conserved motif (Fig. 7B), is essential for the interaction with the trans-acting factors that recognize the TEF1 element (Curie et al. 1992 and unpublished data). It will be interesting to examine whether this sequence, and also the putative ocs sequence, are targets for Arabidopsis nuclear factors.

Functional interaction between the promoter elements. Our results show that during vegetative growth, the activation of the A1 EF- $1 \alpha$ gene is determined by several elements which can be individually responsible for a given tissue-specific pattern of expression. Thus, as discussed above, the sequences downstream to the transcription initiation site contain element(s) which by themselves are sufficient to direct expression in roots. The TEF1 box could be required for the activity in meristems. However, it is clear that the combinatorial properties of both upstream and downstream cis-regulatory elements are required for the overall tissue-specific regulatory program. More direct evidence for such a combinatorial control of gene activation comes from the analysis of expression in leaves (Figs. 2 and 3). A 5 ' deletion, which disrupts the TEF1 box, led to a 300 -fold decrease in GUS activity in rosette leaves and a dramatic decrease in GUS staining both in rosette and cauline leaves, suggesting that the TEF1 box is the major cis-acting element responsible for the activation of the expression in leaves. However, our results demonstrate that sequences of the $5^{\prime}$ IVS are also absolutely required for the expression in leaves. We conclude that the combination of the TEF1 box with the downstream sequences is necessary for the activation of gene expression in leaves. The interaction between the cis-acting elements of the A1 EF- $1 \alpha$ gene promoter is demonstrated by transient expression experiments (Figs. 4 and 5), which show that the activation of gene expression by the TEF 1 box or the $5^{\prime}$ IVS requires specific downstream or upstream sequences, respectively. A similar situation has recently been reported for the human PDGF-B gene (Franklin et al. 1991). This gene is regulated by both positively and negatively acting cell type-specific regulatory elements located within the first intron and specifically requiring the PDGF-B promoter upstream sequences for transcriptional activity.

The Telo box. The conservation of a Telo box (Axelos et al. 1989) located at the same position between the TATA box and TEF1 elements within the four Arabidopsis EF-1 $\alpha$ genes (Liboz et al. 1990), a tomato EF-1 $\alpha$ gene (Shewmaker et al. 1990) and a tobacco gene encoding for thioredoxin (Marty 1992, and Fig. 6), strongly suggests that these sequences play a functional role. This element, homologous to the repeat motif of plant telomeres (Richards and Ausubel 1988), is reminiscent of the yeast RPG box (Leer et al. 1985) involved in the activation of several yeast ribosomal and housekeeping genes (Huet et al. 1985). The RPG box also shows structural homologies with the telomeric repeat of yeast (Buchman et al. 1988). Despite conservation of the Telo box at the same location within several plant promoters and its similarities with the yeast regulatory sequences we have shown that deletion of this box does not significantly affect the expression of the GUS reporter gene either in transient assays (Curie et al. 1991) or in trans- 
genic plants (Fig. 2). One possibility is that the Telo box could be involved in the interaction with the nuclear scaffold and that a redundant but less conserved Telo box found within the A1 promoter (unpublished observations) could fulfill this function. In this context, it must be noted than more than $90 \%$ of RAP-1, the yeast protein interacting with the RPG box, is associated with the nuclear scaffold (Hofmann et al. 1989) and that human telomeres are attached to the nuclear matrix via their CCCTAA repeats (De Lange 1992).

Acknowledgements. We thank Dr. C. Gigot for helpful discussions and D. Douilhac for her technical assistance. We gratefully acknowledge financial support from the Conseil Regional Midi Pyrénées. C.C. holds a grant from the Ministère de la Recherche et de la Technologie.

\section{References}

Atanassova R, Chaubet N, Gigot C (1992) A 126 bp fragment of a plant histone gene promoter confers preferential expression in meristems of transgenic Arabidopsis. Plant J 2:291-300

Axelos M, Bardet C, Liboz T, Le Van Thai A, Curie C, Lescure B (1989) The gene family encoding the Arabidopsis thatiana translation elongation factor EF-1 alpha: molecular cloning, characterization and expression. Mol Gen Genet 219:106-112

Axelos M, Curie C, Mazzolini L, Bardet C, Lescure B (1992) A protocol for transient expression in Arabidopsis thaliana protoplasts isolated from cell suspension cultures. Plant Physiol Biochem 30:123-128

Benfey PN, Chua N-H (1990) The cauliflower mosaic virus 35S promoter: combinatorial regulation of transcription in plants. Science 250:959-966

Benfey PN, Ren L, Chua N-H (1989) The CaMV 35S enhancer contains at least two domains which can confer different developmental and tissue expression patterns. EMBO J 8:2195-2202

Bouchez D, Tokuhisa JG, Llewellyn DJ, Dennis ES, Ellis JG (1989) The ocs-element is a component of the promoters of several T-DNA and plant viral genes. EMBO J 8:4197-4204

Bradford MM (1976) Rapid and sensitive method for the quantitation of microgram quantities of protein utilizing the principle of protein-dye binding. Anal Biochem 72:248-254

Bruhat A, Tourmente S, Chapel S, Sobrier ML, Couderc JL, Dastugue B (1990) Regulatory elements in the first intron contribute to transcriptional regulation of beta 3 tubulin gene by 20 hydroxyecdysone in Drosophila Kc cells. Nucleic Acids Res $18: 2861-2867$

Brujidou C, Marty I, Chartier Y, Meyer Y (1993) The Nicotiana tabacum genome endodes thioredoxin genes which are differentialy expressed. Mol Gen Genet (in press)

Buchman AR, Kimmerly WJ, Rine J, Kornberg RD (1988) Two DNA-binding factors recognize specific sequences at silencers, upstream activating sequences, autonomously replicating sequences, and telomeres in $S$. cerevisiae. Mol Cell Biol 8:210-225

Chung S, Perry RP (1989) Importance of introns for expression of mouse ribosomal protein gene rpL32. Mol Cell Biol 9:20752082

Curie C, Liboz T, Bardet C, Gander E, Médale C, Axelos M, Lescure B (1991) Cis and trans-acting elements involved in the activation of Arabidopsis thaliana A1 gene encoding the translation elongation factor EF-1 alpha. Nucleic Acids Res 19:13051310

Curie C, Liboz T, Montané M-H, Rouan D, Axelos M, Lescure B (1992) The activation process of Arabidopsis thaliana A1 gene encoding the translation elongation factor EF-1 alpha is conserved among angiosperms. Plant Mol Biol 18:1083-1089

De Lange T (1992) Human telomeres are attached to the nuclear matrix. EMBO J 11:717-724
Dobres MS, Thompson WF (1989) A developmentally regulated, bud-specific transcript in pea has sequences similarity to seed lectins. Plant Physiol 89:833-838

Dynan WS (1989) Modularity in promoters and enhancers. Cell $58: 1-4$

Ellis JG, Llewellyn DJ, Walker JC, Dennis ES, Peacock WJ (1987) The ocs element: a 16 base pair palindrome essential for activity of the octopine synthase enhancer. EMBO J 6:3203-3208

Evans MJ, Scrapulla RC (1988) Both upstream and intron sequence elements are required for elevated expression of the rat somatic cytochrome $c$ gene in COS- 1 cells. Mol Cell Biol $8: 35-41$

Franklin GC, Donovan M, Adam GIR, Holmgren L, Pfeifer -Ohlsson F, Ohlsson R (1991) Expression of the human PDGF-B gene is regulated by both positively and negatively acting cell type-specific regulatory elements located in the first intron. EMBO J 10:1365-1373

Fromm H, Katagiri F, Chua N-H (1989) An octopine synthase enhancer element element directs tissue-specific expression and binds ASF-1, a factor from tobacco nuclear extracts. Plant Cell 1:977-984

Hemerly A, Bergounioux C, Van Montagu M, Inze D, Ferreira P (1992) Genes regulating the plant cell cycle: Isolation of a mitotic-like cyclin from Arabidopsis thaliana. Proc Natl Acad Sci USA 89:3295-3299

Hofmann JFX, Laroche T, Brand AH, Gasser SM (1989) RAP-1 factor is necessary for DNA loop formation in vitro at the silent mating type locus $H M L$. Cell 57:725-737

Hovemann B, Richter S, Walldorf U, Cziepluch C (1988) Two genes encode related cytoplasmic elongation factor (EF-1 alpha) in Drosophila melanogaster with continuous and stagespecific expression. Nucleic Acids Res 16:3175-3194

Huet J, Cottrelle P, Cool M, Vignais ML, Thiele D, Mark C, Buhler JM, Sentenac A, Fromageot P (1985) A general upstream binding factor for genes of the yeast translational apparatus. EMBO J 4:3539-3547

Jefferson RA (1987) Assaying chimeric genes in plants: The GUS gene fusion system. Plant Mol Biol Rep 5:387-405

Jefferson RA, Kavanagh TA, Bevan MW (1987) GUS fusions: beta-Glucuronidase as a sensitive and versatile gene fusion marker in higher plants. EMBO J 6:3901-3907

Koning AJ, Tanimoto EY, Kiehne K, Rost T, Comai L (1991) Cell-specific expression of plant histone $\mathrm{H} 2 \mathrm{~A}$ genes. Plant Cell 3:657-665

Lam E, Benfey PN, Gilmartin PM, Rong-Xiang F, Chua N-H (1989) Site-specific mutations alter in vitro factor binding and change promoter expression pattern in transgenic plants. Proc Natl Acad Sci USA 86:7890-7894

Leer RJ, Van Raamsdonk-Duin MC, Mager WH, Planta RJ (1985) Conserved sequences upstream of yeast ribosomal protein genes. Curr Genet 9:273-277

Lendstra JA, Van Vliet A, Arnberg AC, Van Hemert FJ, Möller W (1986) Genes coding for the elongation factor EF-1 alpha in Artemia. Eur J Biochem 155:475-483

Lepetit M, Ehling M, Chaubet N, Gigot C (1992) A plant histone gene promoter can direct both replication-dependent and independent gene expression in transgenic plants. Mol Gen Genet $231: 276-285$

Liboz T, Bardet C, Le Van Thai A, Axelos M, Lescure B (1990) The four members of the gene family encoding the Arabidopsis thaliana translation factor EF-1 alpha are actively transcribed. Plant Mol Biol 14:107-110

Luehrson KR, Walbot V (1991) Intron enhancement of gene expression and the splicing efficiency of introns in maize cells. Mol Gen Genet 225:81-93

Maas C, Laufs J, Grant S, Korfhage C, Werr W (1991) The combination of a novel stimulatory element in the first exon of the maize Shrunken-1 gene with the following intron 1 enhances reporter gene expression up to 1000 -fold. Plant Mol Biol 16:199-207 
Medford JI, Elmer JS, Klee HJ (1991) Molecular cloning and characterization of genes expressed in shoot apical meristems. Plant Cell 3:359-370

Pri-Hadash A, Hareven D, Lifschitz E (1992) A meristem-related gene from tomato encodes a dUTPase: Analysis of expression in vegetative and floral meristems. Plant Cell 4:149-159

Richards EJ, Ausubel FM (1988) Isolation of a higher eukaryotic telomere from Arabidopsis thaliana. Cell 53:127-136

Riis B, Rattan SIS, Clark BFC, Merrick WC (1990) Eukaryotic protein elongation factors. Trends Biochem Sci 15:420-424

Ripe RA, Lorenzen SI, Brenner DA, Breindl M (1989) Regulatory elements in $5^{\prime}$ flanking region and the first intron contribute to transcriptional control of the mouse alpha 1 type collagen gene. Mol Cell Biol 9:2224-2227

Shewmaker CK, Ridge NP, Pokalsky AR, Rose RE, Hiatt WR (1990) Nucleotide sequence of an EF-1 alpha genomic clone from tomato. Nucleic Acids Res 18:4276
Sussex IM (1989) Developmental programming of the shoot meristem. Cell 56:225-229

Tokuhisa JG, Singh K, Dennis ES, Peacock WJ (1990) A DNAbinding protein factor recognizes two binding domains within the octopine synthase enhancer element. Plant Cell 2:215-224

Uetsuki T, Naito A, Nagata S, Kaziro Y (1989) Isolation and characterization of the human chromosomal gene for polypeptide chain elongation factor EF-1 alpha. J Biol Chem 264:57915798

Ursin VM, Irvine JM, Hiatt WR, Shewmaker CK (1991) Developmental analysis of elongation factor- 1 alpha expression in transgenic tobacco. Plant Cell 3:583-591

Valvekens D, Van Montagu M, Van Lijsebettens M (1988) Agrobacterium tumefaciens-mediated transformation of Arabidopsis thaliana root explants by using kanamycin selection. Proc Natl Acad Sci USA 85:5536-5540 